\title{
Dental fluorosis and its burden in India-revisiting a forgotten chapter
}

\author{
Renu Rawat $^{1 *}$, Gunjan S. Aswal ${ }^{2}$, Dinesh F. Swamy ${ }^{3}$, Vishwanath Gurumuthy ${ }^{4}$, \\ Soumya Vishwanath ${ }^{5}$
}

\begin{abstract}
${ }^{1}$ Department of Dental Public Health, University of Manchester, Manchester, UK
${ }^{2}$ Department of Dentistry, Mekelle University, Mekelle, Ethiopia

${ }^{3}$ Department of Paediatric Dentistry, Goa dental college and hospital, Bambolin, India

${ }^{4}$ Department of Dental Technology, King Khalid University, Abha, Saudi Arabia

${ }^{5}$ Consultant Periodontist, All Care Dental Centre, Bengaluru, India
\end{abstract}

Received: 20 June 2020

Accepted: 30 July 2020

\author{
*Correspondence: \\ Dr. Renu Rawat, \\ E-mail: renu.rawat@postgrad.manchestar.ac.uk
}

Copyright: $\odot$ the author(s), publisher and licensee Medip Academy. This is an open-access article distributed under the terms of the Creative Commons Attribution Non-Commercial License, which permits unrestricted non-commercial use, distribution, and reproduction in any medium, provided the original work is properly cited.

\begin{abstract}
"Flouride" mineral is essential for the normal development of bone and teeth. However, its presence in excess of the required limit results in fluorosis of bone (skeletal) and teeth (dental). It is a dominating public health issue in India due to the geographical fluoride belt across numerous states. Dental fluorosis is characterised by the staining and pitting of tooth/teeth. Despite fluoride's anticariogenic potential, when present in excess amounts, deteriorates aesthetics and cripples the physical, mental and social health of individuals. Numerous government-led initiatives are in place to optimize fluoride levels, unfortunately, with limited coverage and constrained time frame. The overview is an endeavour to assemble the breathing information on dental fluorosis and the obliviousness towards this condition devastating many lives in India. In this manner, stressing on the squeezing need of educational and dental treatment mediations alongside rebuilding of defluoridation programs across the nation.
\end{abstract}

Keywords: Fluoride, Fluorosis, Burden, Deflouridation

\section{INTRODUCTION}

In Indian society, oral health continues to be disregarded in contrast to systemic wellbeing. ${ }^{1}$ Oral diseases are typically widespread in hetergeneous populations and disproportionate society, especially among the economically-strained masses. An enormous chunk of the population lack access to any kind of dental care due to the exiguous public understanding of the determinants of oral health, extensive presence of oral diseases and meagre oral health services in the past. $^{2}$

Periodontal diseases, dental caries, malocclusion and oral cancer are dental conditions prevalent in India but less significance has been given to Fluorosis and its adverse effects on the population, which poses a serious threat. ${ }^{3}$ Fluorosis is a dominating public health issue in 24 countries; including India, the reason being the geographical fluoride belt in which India lies. ${ }^{4}$

\section{FLUOROSIS}

Uncontrolled intake of fluoride primarily through drinking water, industrial contamination and food products over a prolonged interval can lead to fluorosis. According to world health organization specification, typical incentive for fluoride is $1.5 \mathrm{mg}$ per litre, with approximately in the range of 0.8 and $1.2 \mathrm{mg}$ per litre in order to augment benefits and curtail damaging effects. Fluoride contamination strikes teeth (dental fluorosis) and bones (skeletal fluorosis) along with long-term excessive exposure induced pain in abdomen, seizures, vomiting and nausea, increased salivary secretion and muscle spasm. ${ }^{5,6}$ (Table 1) 
Table 1: Concentration of Fluoride in Drinking water and its effect on Human Health. ${ }^{7}$

\begin{tabular}{|c|c|}
\hline $\begin{array}{l}\text { Fluoride concentration } \\
\text { (mg/L) } \\
\text { [min-max range] }\end{array}$ & Effect \\
\hline Nil & $\begin{array}{l}\text { Limited growth and } \\
\text { fertility }\end{array}$ \\
\hline$<0.5$ & Dental caries \\
\hline $0.5-1.5$ & $\begin{array}{l}\text { Promotes dental health } \\
\text { and prevents tooth decay } \\
\text { and cavities }\end{array}$ \\
\hline $1.5-4.0$ & $\begin{array}{l}\text { Dental fluorosis, mottling } \\
\text { and pitting of teeth }\end{array}$ \\
\hline $4.0-10.0$ & $\begin{array}{l}\text { Dental and skeletal } \\
\text { fluorosis, pain in the back } \\
\text { and all joints }\end{array}$ \\
\hline
\end{tabular}

\section{DENTAL FLUOROSIS}

Clinically, dental fluorosis is characterised by the staining and pitting of tooth/teeth. In severe cases, entire enamel may also be damaged. The appearances of teeth may be chalky white along with the presence of white, yellow, brown or black spots or streaks on the surface of enamel. ${ }^{8}$ It occurs during developmental stages of tooth formation, children subjected to increased fluoride content develop dental fluorosis. Discolouration is evident when the condition is mild, but in severe cases pitting of enamel can be observed. Both, the primary and permanent dentition are affected. ${ }^{9}$

Various fluorosis indices are used to guage the severity of fluorosis. These are Deans Index, The Thylstrup and Fejeskvov index, Total tooth surface index (TSIF), Fluorosis risk index (FRI), and non-specific descriptive indices such as Developmental defects of enamel. ${ }^{10}$ Deans fluorosis index is the one being usually utilized. However, it has a few limitations. It does not measure fluorosis at different surfaces of tooth and does not focus on the cosmetic significance of the severe fluorosis estimates. To beat such drawbacks, total tooth surface index can be used. ${ }^{11}$

\section{DISPARITIES CAUSED BY DENTAL FLUOROSIS}

Complications does arise in the behaviour and psychology of individuals, affected due to escalation and worldwide prevalence of dental fluorosis which has led to dissatisfaction regarding aesthetics and facial appearance in children and adults. ${ }^{12}$ Most obvious being the smile, second facial feature noted by people which enhances the attractiveness of the face. ${ }^{13}$ Among adolescents, a smile has a profound influence on self-esteem and confidence as they are concerned about their mien. ${ }^{14,15}$ Their mental prosperity and self-regard is disturbed; particularly critical about their appearance, thus, impacting selfcontentment and happiness. ${ }^{16}$
Such circumstances lead to grave public health worries with a colossal impact on wellbeing as well as the living condition of an individual. Despite fluoride's anticariogenic potential, when present in greater amounts it deteriorates aesthetics which in turn impacts the social and biological health where the socio-economically undermined group is at a substantial risk. ${ }^{17}$

\section{DENTAL FLUOROSIS AS A PUBLIC HEALTH BURDEN}

Presence of fluoride universally in the atmosphere, soil and water make humans vulnerable to fluoride exposure through intake of fluoride from sources such as food, water and more recently industrial and pharmaceuticals by-products. Hydrofluorosis being the major component amongst all, increased concentration of fluoride in drinking water has led to tens of millions of dental fluorosis cases throughout the world addressing it as a public health concern. ${ }^{18}$

Fluorosis is an Endemic grappling India since 1937. ${ }^{19}$ Approximately 19 states with 230 districts of India enduring with dental and skeletal fluorosis. ${ }^{20}$ (Table 2) The seriousness of the condition can be assessed with the help of data giving an estimate of around more than one lakh villages and over 10 million people experience the ailment because of water with high fluoride content. ${ }^{21}$

Table 2: Distribution of fluorosis in India. ${ }^{22}$

\begin{tabular}{|ll|}
\hline $\begin{array}{l}\text { Category and } \\
\text { percentage }\end{array}$ & Name of states \\
\hline $\begin{array}{l}\text { I (30\% districts } \\
\text { affected) }\end{array}$ & $\begin{array}{l}\text { Jammu and Kashmir, Delhi, } \\
\text { Kerala and Orissa }\end{array}$ \\
\hline $\begin{array}{l}\text { II (30-50\% districts } \\
\text { affected) }\end{array}$ & $\begin{array}{l}\text { Maharashtra, Karnataka, } \\
\text { Vidharbha and Bihar }\end{array}$ \\
\hline $\begin{array}{l}\text { III (50-100\% districts } \\
\text { affected) }\end{array}$ & $\begin{array}{l}\text { Uttar Pradesh, Rajasthan, } \\
\text { Gujarat, Andhra Pradesh } \\
\text { and Tamil nadu. }\end{array}$ \\
\hline
\end{tabular}

In India, fluorosis as a public health problem is alarming, with around two-third states being fluoride endemic. The geographical fluoride belt and location of India comprises of rocks and in areas with high fluoride substance or soil. Inevitable leaching of fluoride causes an overabundant fluoride level in groundwater. Drinking water being the primary dietary source of fluoride, it affects a large section of the population. ${ }^{23}$

A cross-sectional assessment conducted on Dental fluorosis and Oral health status of 2400 school-going youngsters in the age group of 13-15 years of Chikkaballapur district, Karnataka state reported the estimated prevalence of dental fluorosis of around $41.1 \%$. Subsequently inferred that the oral health of the individuals was poor and high pervasiveness of fluorosis. $^{24}$ 
A comparable report on Dental Fluorosis among school children including chemical analysis of potable water sources in Adpalli PHC, Mulchera, Gadchiroli, Maharashtra, India provided information from various areas. It exposed the dental fluorosis to be highest as $76.62 \%$ in one district (Kalinagar) descending to $39.25 \%$ in another district (Gandhinagar). It was concluded that the psychological and cosmetic impact of dental fluorosis was evident among the population affected by it. ${ }^{25}$

Another evaluation directed on the prevalence of dental fluorosis and associated risk factors in Bagalkot District Karnataka India uncovered comparable data addressing drinking water as the essential cause of dental fluorosis, with malnourished children exhibiting a severe form of fluorosis. ${ }^{26}$

An observational study on the prevalence of dental fluorosis among adolescents in schools of Greater Noida, Uttar Pradesh concluded that water consumed from hand pumps by a majority of the population is amalgamated with the condition of dental fluorosis although it was discovered that here the issue can be considered as of medium public health concern as the observed Community fluoride Index was 1.7 . They examined a total of 1318 school children of which 278 were reported with varying degree of dental fluorosis. ${ }^{27}$

Another study on the prevalence and severity of dental fluorosis among school children in a Northern hilly state of India reported the presence of cases of dental fluorosis in Himachal Pradesh. Although during the time of the study, the prevalence varied between $1.5-7 \%$ in different districts, an earnest need to address dental problems at the earliest was suggested because the water supply (treated water) to a hilly state is difficult or interruptive forcing people to consume water from natural sources. Thus, compounding the possibility of consuming fluoridated water. ${ }^{28}$

An investigation revealed the prevalence of dental fluorosis and dental caries in association with high levels of drinking water fluoride content in a district of Gujarat, India; reported the prevalence of dental fluorosis as $49.26 \%$. Their study revealed that the likelihood of developing fluorosis was higher in the areas with high fluoride content in drinking water. Moreover, it was observed that progress of fluorosis was more as time traversed. ${ }^{29}$

In a study conducted in Davangere, it was observed that dental fluorosis was severe when the concentration of fluoride in drinking water increased. Around $69.4 \%$ of study subjects presented fluorosis. In water suitable for drinking a level of $0.74 \mathrm{ppm}$ fluoride was found to be responsible for objectionable dental fluorosis. The study indicated that among school children in Davangere district dental fluorosis was a major dental public health concern. ${ }^{30}$
Ramesh $\mathrm{M}$ et al conducted a study in Salem district on the prevalence of dental fluorosis and its associated factors in Salem District stated that dental fluorosis was reportedly high amongst children the level of fluoride in water was between $0-3 \mathrm{ppm}$. Moreover, it was noticeable that the appearance of fluorosis was proportional with duration for which people had been residing at places with high fluoride content in water. ${ }^{31}$

The prevalence of dental fluorosis in relation to different fluoride levels in drinking water among school going children in Sarada Tehsil of Udaipur district was estimated. The prevalence of dental fluorosis was revealed to be $69.84 \%$ in the city. Study findings also supported the previous conclusions that an increase in dental fluorosis cases with increase in the fluoride content of water from $0.8-4.1 \mathrm{ppm}$. A strong positive correlation was evident between Community fluoride index (CFI) and fluoride content of drinking water as CFI parameters increased with rising concentration of fluoride in drinking waters. $^{32}$

\section{INTERVENTIONS TO MITIGATE FLUOROSIS}

The treatment for dental fluorosis is extensive and expensive as well as time consuming. Not easily accessible to the rural population. Lack of sustainable treatment options pave way for interventional and preventory approach. ${ }^{33} \mathrm{All}$ the studies highlight various government initiated defluoridation programs. Nalgonda technique is one of them where defluoridation is accomplished by contact precipitation using bone charcoal. Also, incorporation of health education regarding appropriate use of fluorides is recommended to spread awareness regarding the etiology and prevention of dental fluorosis. In fluoride affected territories, mother's ought to be encouraged to breastfeed as fluoride concentration is low in breast milk. Supply of safe drinking water through pipe lines with regulated fluoride content is imperative to ensure its prevention. ${ }^{34}$

The Indian government has sincerely attempted to curb the situation. Numerous government-initiated interventions such as Nalgonda technology -based treatment plan, along with UNICEF smaller defluoridation units for families have been introduced; regional surface water-based pipelines and reverse osmosis plants have been placed. National programme for prevention and control of fluorosis (NPPCF) is also an initiative from the government. However, on critically analysing the situation we can say that although these interventions were fruitful, they worked for very short time frame with limited coverage and could not deliver impacts that could last longer. Essentially because of lack of constant attention to these services and absence of focus on exploring long-term solutions to the problem. ${ }^{35} \mathrm{Also}$, lack of awareness and food and dietary habits in schools are considered to be responsible for the condition. ${ }^{36}$ Thus, stressing the need for interventions in the form of awareness/educational programs. 


\section{CONCLUSION}

In light of the reliable and consistent findings from various studies on dental fluorosis, it could be reasoned that dental fluorosis is an endemic grappling a huge segment of the country. It deteriorates the physical and psychological well-being of the individuals. Therefore, it ought to be regarded as a public health issue calling for immediate measures to curb it at the earliest.

Finally, to summarize, the various factors contributing to the distribution of dental fluorosis and resultant inequality in health can be enumerated as presence of fluoride in the drinking water beyond the safe limits $(>1.5 \mathrm{mg} / \mathrm{l})$; inaccessible treated water to the households thus forcing the residents to drink water/ use water for cooking purposes from the natural sources rich in fluoride; interventional programs with short-term goals; insufficient number of defluoridation programs and unsatisfactory maintenance. Scarce information regarding such programs and their benefit's outreach; deficient awareness among the population regarding the etiology and various sources of fluoride (drinking water, water used for cooking, food intake, early signs of fluorosis, geographic fluoride belt); Most significantly, lack of proactive response of the government to identify and eliminate the public health problem of dental fluorosis on a large scale in the form of awareness campaigns, defluoridation programs and dental treatment camps.

\section{Funding: No funding sources \\ Conflict of interest: None declared \\ Ethical approval: Not required}

\section{REFERENCES}

1. IDA. National Oral Health Programme; optimal oral health for all by 2020 Report.

2. Nair RB. World oral health day: What India can do to improve its smile. In: Huffpost 2015.

3. The World oral health report 2003.World health organization Report.

4. Dubey S, Agarwal M, Gupta BA. Recent development in defluoridation of drinking water in India. International conference on Water, Environment, Energy \& Society, Bhopal, 2016.

5. Smriti K. Huge population at fluorosis risk. The Hindu newspaper.2014.

6. Sharma NC. India's 11.5 million people at risk of fluorosis due to lack of clean drinking water. livemint. 2017.

7. Weish, Hattab FN, Mellberg JR. Concentration of fluoride and selected other elements in teas. Department of children's dentistry and orthodontics, University of Hong Kong.Nutrition.1989;5(4):23740.

8. Soni R, Modi S. A review on effects of fluoride on human health in Rajasthan. Int. J. Innov. Res. Dev. 2013;2(4):638-46.
9. Moimaz SA, Salibao, Marques LB et al. Dental fluorosis and its influence on children's life. Braz oral Res. 2015;29:43-8.

10. Nor NM. Methods and indices in measuring fluorosis. A review. Arch Orofas Sci.2017;12(2):7785.

11. Horowitz HS. Indices for measuring dental fluorosis. J public health Dent. 1986;46(4):179-83.

12. Hasserbrauck M. The visual process method: A new method to study physical attractiveness. Evol.Hum. Behav.1998;19:111-23.

13. Marshman Z, Gibson B, Robinson PG. The impact of developmental defects of enamel on young people in the UK. Community Dent.OralEpidemiol.2008; $37: 45-57$.

14. Coffield KD, Phillips C, Brady M et al. Psychosocial impact of developmental dental defects in people with hereditary amelogenesis imperfecta. J.Am.Dent.Assoc.2005;136:620-30.

15. Flores MC, Silver E, Barriga ML et al. Lay person's perception on smile aesthetics in dental and facial views. J. orthod.2004;31:204-9.

16. Frechero NM, Rascon MN, Raxon AN et al. Impact of dental fluorosis, socioeconomic status and selfesteem and self-perception in adolescents exposed to a high level of fluoride in water. Int J.Environ Res Public Health. 2017;14(1):73-8

17. Browne DD. Enamel fluorosis: a cause for concern. Journal of the Irish Dental Association. 2012;58(3): S10-S13.

18. Mohanta A, Mohanty PK. Dental fluorosisRevisited. Biomed J Sci \& Tech Res 2018; 2(1).14-6.

19. Shortt HE, Pandit CG, Raghvachari TNS. Endemic fluorosis in Nellore district of south India. Indian Medical Gazettiar.1937;72:396-400.

20. Shetti S, Patil A, Khairnar M et al. Estimation of fluoride level in drinking water and prevalence of dental fluorosis in Vairag village of Solapur district, Maharashtra, India: a cross sectional study. OMICS International.2016;6:275-9.

21. Taneja R. How fluorosis is crippling India and needs urgent attention. NDTV org 2016. Available from URL:https://everylifecounts.ndtv.com/.Assesed on15 June 2020

22. Harish A, Sanjeev J, Chachada A et al. Mysterious prevalence of dental fluorosis in Waghdhara. Int J In Res Rev. 2017; 4(7):4326-8.

23. Ali S. Thakur SK. Sarkar A. Shekhar S. Worldwide contamination of water by fluoride. Environ Chem Lett. 2016; 14(3):291-315.

24. Shetty P, Shamala A, Murali R, Mansi Y et al. Dental fluorosis and oral health status of 13-15-year-old school children of Chikkaballapur district: A cross sectional study. J Indian Assoc Public Health Dent.2017;15(2):140-4.

25. Samal J, Rathod PK. A cross sectional study on dental fluorosis among school children including chemical analysis of potable water sources in Adpalli PHC, Mulchera, Gadchiroli, Maharashtra India. J Biologi Sci Opinion.2013;1(2):77-80. 
26. Mahantesha T, Dixit UB, Nayakar RP et al. Prevalence of dental fluorosis and associated Risk factors in Bagalkot district, Karnataka, India. Int $\mathrm{J}$ Clin Pediatr Dent.2016;9(3):256-63.

27. Chaudhary M, Prabhakar I, Gupta B et al. Prevalence of Dental Fluorosis among adolescents in school of greater Noida, Uttar Pradesh J Indian Assoc Public Health Dent.2017;15(1):36-41.

28. Chauhan D, Chauhan T, Sachdev V, Kirtaniya BC. A study of prevalence and severity of dental fluorosis among school children in a northern hilly state of India. SRM J Res Dent Sci.2013;3(3):170-4.

29. Kotecha PV, Patel SV, Bhalani KD et al. Prevalence of dental fluorosis \& dental caries in association with high levels of drinking water fluoride content in a district of Gujarat,India. Indian J Med Res.2012;135(6):873-7.

30. Chandrashekar J, Anuradha KP. Prevalence of dental fluorosis in rural areas of Davangere India. Int Dent J.2004; 54(5):235-9.

31. Ramesh M, Narasimhan M, Krishnan $R$ et al. The prevalence of dental fluorosis and its associated factors in Salem district. Contem Clin Dent.2016;7(2):203-8

32. Arora R, Bhayya D, Mehta DN, Savvaiya BU. Prevalence of dental fluorosis in relation with different fluoride levels in drinking water among school going children in Sarda tehsil of Udaipur district, Rajasthan. J Indian Soc Pedod Prev Dent. 30(4):317-22.

33. Khairnar MR, Dodamani AS, Jadhav HC et al. Mitigation of fluorosis-A review.

J Clin Diagn Res.2015;9(6):5-9.

34. Piddennavar R, Krishnappa P. Review on defluoridation techniques of water. Int $\mathrm{J}$ Eng Sci.2013;2(3):86-94.

35. Fluoride India. Medium.2016. Available from- A medium corporation https://medium.com/fluorideindia/freedom-fromfluorosis-how-long-will-it-take-74617f18961e. Assessed on 15 June 2020.

36. Rustagi N, Rathore AS, Meena JK et al. Neglected health literacy undermining fluorosis control efforts: A pilot study among school children in an endemic village of rural Rajasthan, India. J Family Med Prim Care.2017;6(3):533-7.

Cite this article as: Rawat R, Aswal GS, Swamy DF, Gurumuthy V, Vishwanath S. Dental fluorosis and its burden in India-revisiting a forgotten chapter. Int J Community Med Public Health 2020;7:3730-4. 